\title{
Clinical Reasoning: A 73-year-old man with recurrent aphasia, headaches, and confusion
}

Gauruv Bose, MD, Tess Fitzpatrick, MD, Vignan Yogendrakumar, MD, Jocelyn Christine Zwicker, MD, and Gerard Jansen, MD

Neurology ${ }^{\circledR}$ 2020;95:e2595-e2599. doi:10.1212/WNL.0000000000010475
Correspondence

Dr. Bose

gbose@toh.ca

\section{Section 1}

A 73-year-old man presented with sudden right-sided weakness, aphasia, and low-grade headache. Medical history was pertinent for obstructive sleep apnea, hypertension, diabetes, and dyslipidemia, for which he was appropriately treated, in addition to taking aspirin for primary prevention. Initial bloodwork, head CT, and vessel imaging were normal. MRI showed a nonenhancing, nonrestricting T2 hyperintensity in the left temporal lobe, in addition to multiple microhemorrhages (figure 1, A and B). Symptoms resolved within 24 hours and he was discharged on a second antiplatelet agent (clopidogrel). Three weeks later, a second episode of aphasia and rightsided weakness occurred, resolving within hours. He returned to the hospital the following day as symptoms recurred again. He had had been continually complaining of headaches, and his family had noted a gradual cognitive decline over the past month. Repeat bloodwork and erythrocyte sedimentation rate were normal. MRI demonstrated persistent microhemorrhages and superficial siderosis, worsening of the left temporal lobe subcortical changes, as well as diffuse leptomeningeal enhancement.

\section{Questions for consideration:}

1. What is the differential diagnosis for recurrent neurologic symptoms?

2. What investigations ought to be considered given this differential and MRI findings?

GO TO SECTION 2 


\section{Section 2}

The differential included TIA, although lack of diffusion restriction on MRI and stereotyped events despite normal vessel imaging made this less likely. An echocardiogram and 72-hour Holter monitor were done and also normal. Recurrent events are typical of focal seizures, and given the increasing temporal lobe hyperintensity, a low-grade glioma was a potential cause and levetiracetam was initiated. A routine 1-hour EEG was performed and did not capture any clinical events or epileptic abnormalities; however, the medication was continued. The patient's age, headaches, and focal neurologic symptoms prompted investigation for giant cell arteritis, though erythrocyte sedimentation rate was normal.

The leptomeningeal enhancement was investigated with CSF analysis, which showed marked elevation in protein at $1.87 \mathrm{~g} / \mathrm{L}$; however, there were zero total nucleated or red blood cells/ $\mu \mathrm{L}$, gram stain was negative, CSF glucose was normal, no oligoclonal bands were detected, and flow cytometry and cytology testing were negative for malignancy. No opening pressure was obtained. Given the absence of total nucleated cells, and lack of fever, herpes simplex virus was not sent despite the temporal lobe abnormality on MRI. The elevated protein was suggestive of an inflammatory etiology, yet vessel imaging did no show changes suspected for primary angiitis of the CNS (PACNS), and a chest CT was performed that did not show hilar lymphadenopathy that can be seen in sarcoidosis. Despite a negative CSF cytology and flow cytometry, lymphoma was still a potential differential and a CT abdomen and pelvis was performed without abnormality.

The clinical course of recurrent neurologic symptoms, headache, and cognitive decline, presence of multiple microhemorrhages with superficial siderosis and leptomeningeal enhancement, and inflammatory CSF analysis was suggestive of $\beta$-amyloid-related angiitis (ABRA).

\section{Questions for consideration:}

1. What further investigations would assist in the diagnostic clarification for this patient?

2. What is the definition and treatment of ABRA?

Figure $1 \mathrm{MRI}$ characteristic of $\beta$-amyloid-related angiitis

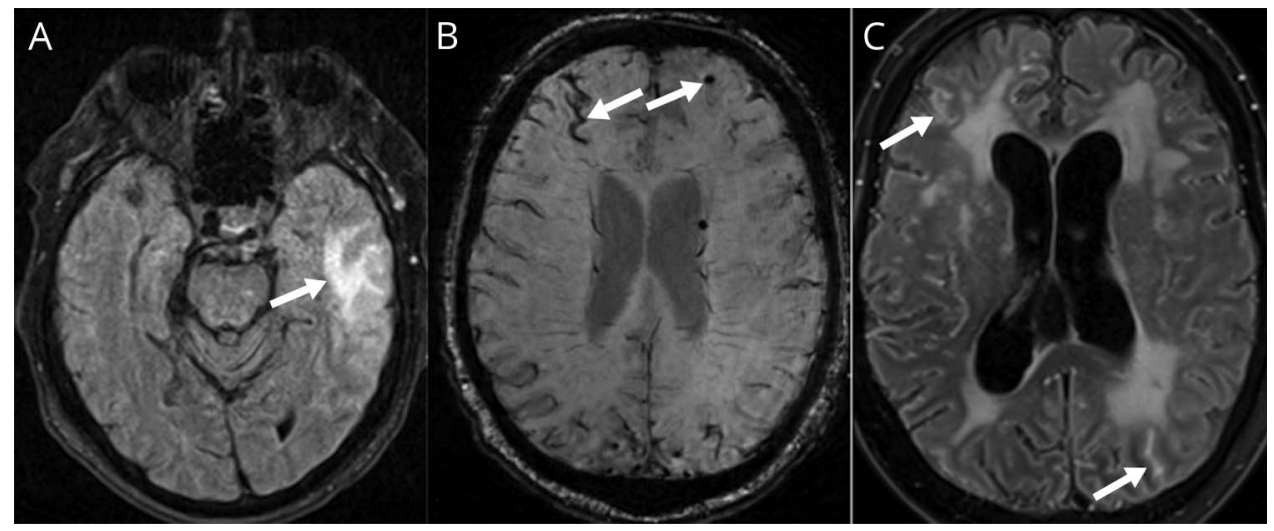

(A) T2 fluid-attenuated inversion recovery image showing left temporal lobe hyperintensity (arrow). (B) Susceptibility-weighted image showing microhemorrhages and superficial siderosis (arrows). (C) Six-month gadolinium-enhanced T2 fluid-attenuated inversion recovery showing leptomeningeal enhancement (arrows). 


\section{Section 3}

Treatment for the presumed diagnosis of ABRA was initiated with a 5-day course of IV methylprednisolone $1,000 \mathrm{mg}$ daily followed by oral prednisone $50 \mathrm{mg}$ per day, and clopidogrel was discontinued. Brain biopsy and cyclophosphamide were recommended, but the headaches, neurologic examination, and leptomeningeal enhancement improved. Consequently, the patient and his family deferred brain biopsy with sampling of parenchyma and meninges, the gold standard test for ABRA. The patient's cognitive testing initially improved from a Montreal Cognitive Assessment of 20/30 to 24/30 after 1 month of therapy, but he remained fatigued, attributed to steroid use, and weaned to $40 \mathrm{mg}$ daily 1 month postdischarge. Two months postdischarge, methotrexate was added to prednisone to reduce risk of ABRA recurrence. Despite these adjustments, the patient's fatigue worsened and his cognition progressively declined.

Six months postdischarge, the confusion had progressed, headaches worsened, and the patient developed gait difficulty prompting return to hospital. Bloodwork including absolute neutrophil count, thyroid, liver, and renal function, and serum inflammatory markers including erythrocyte sedimentation rate, antinuclear antibody, and antineutrophil cytoplasmic antibody were normal. An infectious workup for HIV, syphilis, and Lyme borreliosis was negative. Repeat CSF analysis yielded protein elevation at $1.06 \mathrm{~g} / \mathrm{L}$, slightly less than previously; and again, zero total nucleated cells or red blood cells were detected, cytology was negative, CSF glucose was normal, and gram stain, fungal culture, and mycobacterium culture were negative. Opening CSF pressure was not obtained. Creutzfeldt-Jakob disease testing with CSF 14-3-3, tau, and endpoint quaking-induced conversion assay were negative. Both serum and CSF paraneoplastic and autoimmune antibody panels were negative. Repeat CT chest, abdomen, and pelvis were negative. MRI showed resolution of the previously observed left temporal hyperintensity, but development of a new left parietal infarct with petechial hemorrhages, as well as worsening leptomeningeal enhancement (figure 1C).

\section{Questions for consideration:}

1. What could be the reason for the patient's worsening?

2. Are there any further tests that would be helpful in this patient's case?

GO TO SECTION 4 


\section{Section 4}

Due to concern for ABRA recurrence, a course of IV immunoglobulin G $2 \mathrm{~g} / \mathrm{kg}$ over 5 days followed by IV methylprednisolone $1,000 \mathrm{mg}$ daily for 5 days was delivered. Brain biopsy and cyclophosphamide were again recommended; however, as the patient's cognitive status and expected quality of life were guarded, after discussion with the family, no further diagnostic investigations or treatments were pursued. The patient died and autopsy was performed.

Neuropathologic examination revealed significantly thickened arachnoid and a $4 \times 2.5 \times 3.5 \mathrm{~cm}$ subacute left parietal infarct. At microscopy throughout the cerebral hemispheres, $\beta$-amyloid accumulation was found within intracortical and arachnoidal artery and arteriole walls, at times fragmented (figure 2A), and focally surrounded by mononuclear inflammatory cells. Focal hemosiderin was noted in the arachnoid. In addition to this first process, the arachnoid was filled with granulomas (figure 2B) with halo-surrounded budding organisms in keeping with Cryptococcus sp yeast (figure 2C). The arachnoid near to the infarct was especially involved, and the arteries showed obliterating endarteritis, likely causing the infarct.

\section{Questions for consideration:}

1. What are the risk factors for developing cryptococcal meningoencephalitis?

2. What is the diagnostic yield of CSF culture for Cryptococcus $s p$ yeast and what is the most specific and sensitive test?

3. What is the treatment for cryptococcal meningoencephalitis? What is the prognosis?

\section{Discussion}

Cryptococcus neoformans is a yeast responsible for 30-66 infections in the United States annually and is the most common fungal infection of the CNS worldwide. ${ }^{1}$ In patients with HIV with CD 4 count less than 100 cells/ $\mu \mathrm{L}$ in the United States, incidence of cryptococcal meningoencephalitis may be as high as $3 \% .^{2}$ In HIV-negative patients who are immunocompromised, as in our patient, there may not be signs of raised intracranial pressure (ICP) or disseminated fungicemia. CSF analysis may show increased opening pressure, elevated total nucleated cell counts of $20-200$ cells $/ \mu \mathrm{L}$ of predominantly monocytes, and hypoglycorrhachia, which was not the case in our patient, although elevated CSF protein is also reported. ${ }^{3}$ Gram stain is typically normal with Cryptococcus neoformans due to resemblance to host lymphocytes, and fungal culture is often normal. However, cryptococcal antigen in CSF can be detected quickly with either latex agglutination test assays or enzyme-linked immunoassays that both yield sensitivities and specificities over $90 \%$, and has been reported to be present 3 weeks prior to neurologic symptoms. ${ }^{4}$ Treatment of cryptococcal meningoencephalitis requires antifungals, control of raised ICP, and reducing immune suppression. Induction with IV amphotericin B plus oral flucytosine for at least 6 weeks in patients with neurologic involvement, followed by oral fluconazole for an additional 8 weeks, is recommended. ${ }^{5}$ The prognosis is dependent on underlying comorbidity and cryptococcal antigen titers, but even with prompt adequate treatment, mortality may be $10 \%-30 \%{ }^{6}$

Patients may have nonspecific symptoms, such as headaches, cognitive changes, and ataxia, with either cryptococcal meningoencephalitis or ABRA. Furthermore, CSF analysis in ABRA can also show increased opening pressure, elevated protein, and total nucleated cells. MRI may not differentiate ABRA from cryptococcal meningoencephalitis, as both may show leptomeningeal enhancement, cerebral atrophy, or hydrocephalus, and occasionally cerebral infarcts, as in our patient. ${ }^{7}$ Clinical and radiographic findings can have high likelihood of detecting ABRA, but require absence of neoplastic, infectious, or other

Figure 2 Microscopic examination postmortem demonstrating findings of $\beta$-amyloid (A $\beta$ )-related angiitis and cryptococcal meningoencephalitis
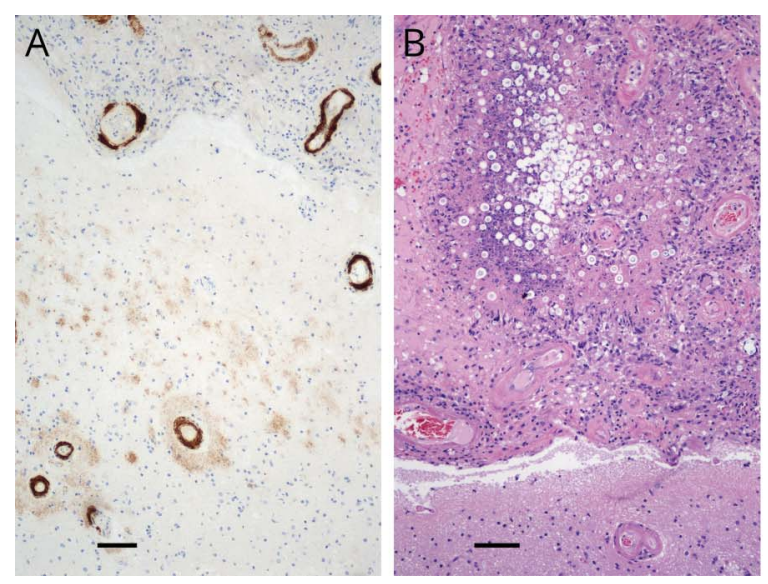

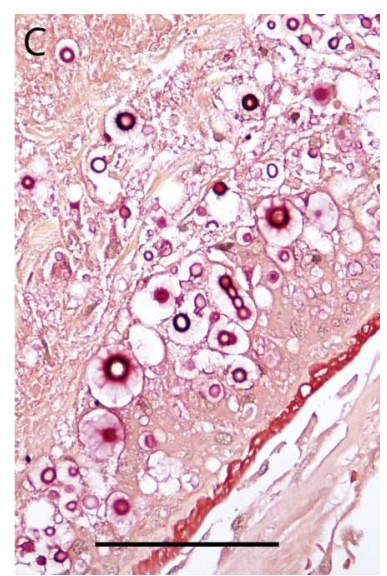

(A) $A \beta$ antibody staining showing $A \beta$ accumulation within cortical arterioles, occasionally with irregular interruptions due to previous amyloid phagocytosis. (B) Granulomatous inflammation of arachnoid (hematoxylin \& eosin). (C) Arachnoid with mucin carmine showing Cryptococcus species organisms. Size bar indicates $100 \mu \mathrm{m}$. 
cause. ${ }^{8}$ Thus, biopsy of brain parenchyma or meninges with examination of vasculature is needed for definitive diagnosis. Tissue biopsy in ABRA will show $\beta$-amyloid accumulation within the regions of vasculitic vessel wall destruction, as was seen in our patient on autopsy, and differentiates from PACNS, sarcoidosis, or intravascular lymphoma. Initiation of immune suppressive medication improves outcomes in ABRA, as seen initially for our patient's clinical symptoms, cognitive testing, reduced CSF protein, and resolution of the left temporal lobe lesion. ${ }^{9}$ The subsequent immunocompromised state can leave a patient susceptible to opportunistic infections, which may have been the sequence of events resulting in cryptococcal meningoencephalitis in our patient.

A high index of suspicion for cryptococcal meningoencephalitis in patients on immune suppression with nonspecific symptoms, and testing CSF cryptococcal antigen, is important as this is a potentially treatable entity with high mortality.

\section{Study funding}

No targeted funding reported.

\section{Disclosure}

The authors report no disclosures relevant to the manuscript. Go to Neurology.org/N for full disclosures.

\section{Appendix Authors}

\begin{tabular}{lll}
\hline Name & Location & Contribution \\
\hline Gauruv Bose, MD & $\begin{array}{l}\text { The Ottawa } \\
\text { Hospital, University } \\
\text { of Ottawa, Canada }\end{array}$ & $\begin{array}{l}\text { Collected and synthesized } \\
\text { the data, drafted the } \\
\text { manuscript for intellectual } \\
\text { content }\end{array}$ \\
\hline
\end{tabular}

Appendix (continued)

\begin{tabular}{lll}
\hline Name & Location & Contribution \\
\hline $\begin{array}{l}\text { Tess Fitzpatrick, } \\
\text { MD }\end{array}$ & $\begin{array}{l}\text { The Ottawa } \\
\text { Hospital, University } \\
\text { of Ottawa, Canada }\end{array}$ & $\begin{array}{l}\text { Collected and synthesized } \\
\text { the data, drafted the } \\
\text { manuscript for intellectual } \\
\text { content }\end{array}$ \\
\hline $\begin{array}{l}\text { Vignan } \\
\text { Mogendrakumar, }\end{array}$ & $\begin{array}{l}\text { The Ottawa } \\
\text { Hospital, University } \\
\text { of Ottawa, Canada }\end{array}$ & $\begin{array}{l}\text { Revised the manuscript for } \\
\text { intellectual content }\end{array}$ \\
\hline $\begin{array}{l}\text { Jocelyn C. } \\
\text { Zwicker, MD }\end{array}$ & $\begin{array}{l}\text { The Ottawa } \\
\text { Hospital, University } \\
\text { of Ottawa, Canada }\end{array}$ & $\begin{array}{l}\text { Revised the manuscript for } \\
\text { intellectual content }\end{array}$ \\
\hline $\begin{array}{l}\text { Gerard H. Jansen, } \\
\text { MD }\end{array}$ & $\begin{array}{l}\text { The Ottawa } \\
\text { Hospital, University } \\
\text { of Ottawa, Canada }\end{array}$ & $\begin{array}{l}\text { Collected and synthesized } \\
\text { the data; drafted the } \\
\text { manuscript for intellectual } \\
\text { content }\end{array}$ \\
\hline
\end{tabular}

\section{References}

1. Góralska K, Blaszkowska J, Dzikowiec M. Neuroinfections caused by fungi. Infection 2018;46:443-459.

2. McKenney J, Bauman S, Neary B, et al. Prevalence, correlates, and outcomes of cryptococcal antigen positivity among patients with AIDS, United States, 1986-2012. Clin Infect Dis 2015;60:959-965.

3. Pappas PG. Cryptococcal infections in non-HIV-infected patients. Trans Am Clin Climatol Assoc 2013;124:61-79.

4. Tanner DC, Weinstein MP, Fedorciw B, Joho KL, Thorpe JJ, Reller L. Comparison of commercial kits for detection of cryptococcal antigen. J Clin Microbiol 1994;32:1680-1684.

5. Dismukes WE, Cloud G, Gallis HA, et al. Treatment of cryptococcal meningitis with combination amphotericin B and flucytosine for four as compared with six weeks. N Engl J Med 1987;317:334-341.

6. Pappas PG, Perfect JR, Cloud GA, et al. Cryptococcosis in human immunodeficiency virus-negative patients in the era of effective azole therapy. Clin Infect Dis 2001;33:690-699.

7. Salvarani C, Morris JM, Giannini C, Brown RD, Christianson T, Hunder GG. Imaging findings of cerebral amyloid angiopathy, A $\beta$-related angiitis (ABRA), and cerebral amyloid angiopathy-related inflammation. Medicine 2016;95:e3613.

8. Auriel E, Charidimou A, Gurol ME, et al. Validation of clinicoradiological criteria for the diagnosis of cerebral amyloid angiopathy-related inflammation. JAMA Neurol 2016;73:197.

9. Corovic A, Kelly S, Markus HS. Cerebral amyloid angiopathy associated with inflammation: a systematic review of clinical and imaging features and outcome. Int J Stroke 2018;13:257-267. 


\section{Neurology}

\section{Clinical Reasoning: A 73-year-old man with recurrent aphasia, headaches, and confusion}

Gauruv Bose, Tess Fitzpatrick, Vignan Yogendrakumar, et al.

Neurology 2020;95;e2595-e2599 Published Online before print August 4, 2020

DOI 10.1212/WNL.0000000000010475

This information is current as of August 4, 2020

\section{Updated Information \&} Services

References

Subspecialty Collections

Permissions \& Licensing

Reprints including high resolution figures, can be found at: http://n.neurology.org/content/95/18/e2595.full

This article cites 9 articles, 1 of which you can access for free at: http://n.neurology.org/content/95/18/e2595.full\#ref-list-1

This article, along with others on similar topics, appears in the following collection(s):

All Cerebrovascular disease/Stroke

http://n.neurology.org/cgi/collection/all_cerebrovascular_disease_strok e

All Clinical Neurology

http://n.neurology.org/cgi/collection/all_clinical_neurology

All Headache

http://n.neurology.org/cgi/collection/all_headache

Fungal infections

http://n.neurology.org/cgi/collection/fungal_infections

Vasculitis

http://n.neurology.org/cgi/collection/vasculitis

Information about reproducing this article in parts (figures,tables) or in its entirety can be found online at:

http://www.neurology.org/about/about_the_journal\#permissions

Information about ordering reprints can be found online:

http://n.neurology.org/subscribers/advertise

Neurology ${ }^{\circledR}$ is the official journal of the American Academy of Neurology. Published continuously since 1951, it is now a weekly with 48 issues per year. Copyright () 2020 American Academy of Neurology. All rights reserved. Print ISSN: 0028-3878. Online ISSN: 1526-632X.

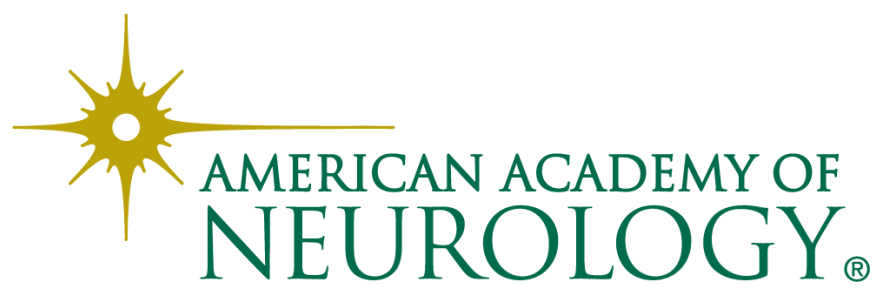

